\title{
The Plasma Preincubation with Papain Before the Assay Suggests that a Gell and Coombs Type II Reaction is Been Demonstrated by the Leukocyte Adherence Inhibition Test
}

\author{
Celso Eduardo Olivier*, Regiane Patussi dos Santos Lima, Daiana Guedes Pinto and Raque \\ Acácia Pereira Gonçalves dos Santos \\ Instituto Alergoimuno de Americana, Brazil
}

*Corresponding author: Celso Eduardo Olivier, Instituto Alergoimuno de Americana, Rua Cuba, 836 - Americana, São Paulo, Brazil

\section{ARTICLE INFO}

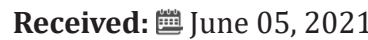

Published: 彗 June 16, 2021

Citation: Celso Eduardo Olivier, Regiane Patussi dos Santos Lima, Daiana Guedes Pinto, Raquel Acácia Pereira Gonçalves dos Santos. The Plasma Preincubation with Papain Before the Assay Suggests that a Gell and Coombs Type II Reaction is Been Demonstrated by the Leukocyte Adherence Inhibition Test. Biomed J Sci \& Tech Res 36(3)-2021. BJSTR. MS.ID.005869.

Keywords: Leukocyte Adherence Inhibition Test (MeSH ID D007957); Immunoassay (MeSH ID D007118); Papain (MeSH ID 10206); Hypersensitivity (MeSH ID D006967)

Abbreviations: LA: Leukocyte Adherence; LAR: Leukocyte Adherence Ratio; LAI: Leukocyte Adherence Inhibition; LAIT: Leukocyte Adherence Inhibition Test; LMI test: Leukocyte Migration Inhibition test

\section{ABSTRACT}

Background: The Leukocyte Adherence Inhibition Test (LAIT) is an ex vivo challenge test used to testimony specific immunoreactivity. Despite numerous studies had been performed to elucidate the interactions involved in the assay, there are yet several questions about its mechanisms and how to translate its results into the medical practice.

Objectives: To perform an experiment with an antibody disassembler: the papain, to demonstrate the participation of specific antibodies in the reconnaissance phase of the assay performed with protein antigens.

Methods: Paired side-by-side ex vivo allergen-specific challenges monitored by the LAIT, were performed with the plasma of allergic patients, preincubated (or not) with papain.

Results: The mean of the differences $(26.66 \%)$ of the two arms was considered significative by the paired t-test ( $\mathrm{p}$-value $<0.05$ ).

Conclusion: Our results suggests that the leukocyte adherence inhibition phenomenon and its inhibition is possibly mediated by an interaction of cells and specific antibodies and deserves further studies as an ex vivo challenge test tool for research of Gell \& Coombs type II hypersensitivity reactions.

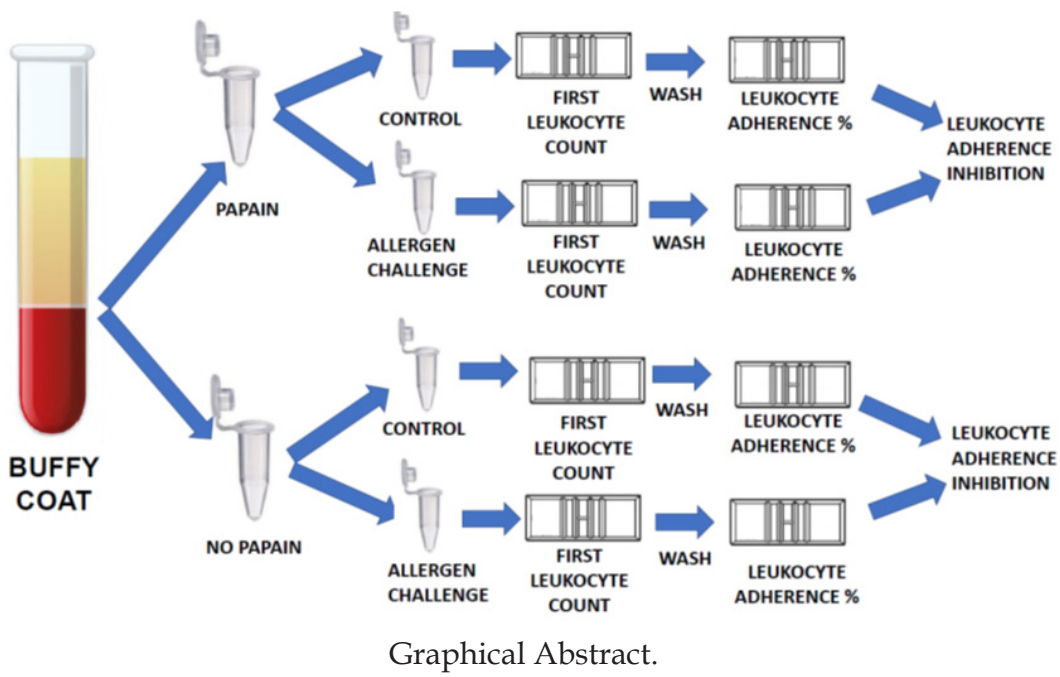




\section{Introduction}

Leukocytes are immune cells that play a key role in vertebrate physiology. It is their capacity of adherence and mobilization that protects the host providing inflammation, expelling of foreign bodies and killing of microorganisms in order to allow cicatrization of injured tissues [1]. Unfortunately, their disfunction, whether by hyperactivity or inactivity, also produces diseases [2]. This is easy to understand because allergic responses are amplified cascade inflammatory reactions that rely on multiples sequential steps, as well on the control of several modulators [3]. To mobilize defenses, leukocytes depend on cytokines, antibodies, surface receptors and adhesion molecules [4]. Adhesion molecules are cytokineregulated glycoproteins expressed on the surface of leukocytes that mediate the adhesion of immune cells to foreign bodies and regulate the recruitment and migration of circulating cells through compromised tissues towards the inflamed site [5-7]. The inhibition of the leukocyte capability of migration induced by specific antigens (ex vivo challenges) was first studied by Boyden, who designed a migration chamber specially to perform the Leukocyte Migration Inhibition Test (LMI test) [8]. Within the same perspective, to study the inhibition of leukocyte adherence, following ex vivo challenges with specific antigens, Halliday designed the Leukocyte Adherence Inhibition Test (LAIT) [9]. Leukocyte's migration and adhesion are intimately related since the inhibition of adhesion also paralysis migration [10]. This interrelationship explains the equivalence that correlates the immunoassays comparing the inhibition of migration with the inhibition of adhesion of leukocytes [11].

Live and rest leukocytes in physiologic conditions have the natural capacity to adhere to glass, property easily recognized by an artisanal immunoassay done with help of a glass surface of a tube and/or a hemocytometer chamber, an optical microscope and a laboratory water bath [12]. This general capacity, however, is lost when the leukocytes are functionally engaged with a particular antigen [13]. When activated in the presence of a specific antigen, leukocytes release soluble factors (cytokines) that recruit nearby leukocytes abolishing their natural capacity of glass adherence and migration [14]. The quantification of the antigen-specific inhibition of leukocyte adherence and/or migration are/is evaluated by the comparison of an antigen-challenged assay with a concomitant control assay done with the unchallenged plasma [15]. Since several mechanisms have been implied as participants of these phenomena, the failure to migrate and/or to adhere to glass seems to be just the final indicator of the antigen-specific leukocyte activation characterized by the cytokines liberation or, to describe with a single word: the immunoreactivity [16-19].

After the initial studies of Halliday and co-works, several scientists evaluated the ex vivo challenges monitored by the LAIT and/or the LMI test to demonstrated immunoreactivity to specific antigens, in order to understand the role of these antigens in health and disease [20-25]. The studies were also directed to identify the specific cytokines involved in the inhibition of the adherence/ migration phenomena, as well their analytical interferents and pharmacological inhibitors [26-28]. But the liberation of cytokines is just the consequent response of the reconnaissance of the specific antigen. We, particularly, were intrigued to respond the question: "Is this cell-mediated phenomenon initiated by specific antibodies?" Whatsoever, the specificity and the prompt response to respond to challenging antigens suggests that an adaptive immune mechanism is involved with the presence of free and/ or membrane-bound specific antibodies. As we observed, it's enough just 30 minutes in contact with the specific antigen at an agitation device at physiologic temperature to generate the specific inhibition of the leukocyte adherence and/or the migration [29]. The involvement of immune cells and antibodies in the context of a hypersensitivity disease characterizes the general definition of a type II Gell and Coombs' reaction. The so-called type II Gell and Coombs' hypersensitivity reactions includes a wide variety of immune mechanisms that possess in common the participation of immune cells and antibodies such as IgG and/or IgM [30].

Usually the Gell and Coombs' type I reaction is defined by the interaction of IgE and mast cells, but now a days we known that IgE can also binds and interacts with circulant immune cells, such as neutrophils, lymphocytes, monocytes, basophils and eosinophils and, at least conceptually, is able to participate of type II reactions [31-35]. Despite the original description of Gell and Coombs had generally named the type II reaction as "cytotoxic", theirs subsequent textbook explanation recognized that some of these reactions were not necessarily deleterious to tissue, but could instead have a stimulatory effect inducing immune modulation or a blast transformation [30]. For a long time, the type II reaction was called "Antibody-Dependent Cellular Cytotoxicity" (ADCC), however, modern classification of hypersensitivity reactions divides type II reactions between type IIa (Antibody-mediated cytotoxic reactions) and type IIb (Antibody-mediated cellstimulating reactions) [36]. The knowledge of the participation of antibodies in the reconnaissance phase of the cell mediated reactions demonstrated by LAIT would not define necessarily if the subsequent effector response will develop a type IIa or type IIb immune reaction, because the LAIT only evaluates the three initial steps of the reaction to specific antigens, i.e.: reconnaissance, cytokine liberation and cellular activation. To clarify this, other immunoassays are required to complete the puzzle, such as, for example, the in vivo skin and provocation tests, the in vitro research of precipitins, the evaluation of the activity of complement system and the dosage of immune complexes and specific antibodies. Anyway, to evaluate the participation of antibodies in the chain of reactions that result in the abolition of leukocyte adherence observed in the ex vivo challenge tests monitored by LAIT, we 
designed a very simple experiment with a very-well studied antibody disassembler: the papain. Papain, also known as papaya proteinase, I, is a cysteine protease (EC 3.4.22.2) obtained from the fresh latex of unripe fruits of Carica papaya and/or Vasconcellea cundinamarcensis [37]. Papain promotes the endolytic hydrolysis of proteins with broad specificity for peptide bonds, especially amino acids bearing a large hydrophobic side chain at the second position at the cleavage site [38]. Papain acts by a catalytic dyad mechanism involving a nucleophilic cysteine thiol [39].

Since the early fifties, when Nobel laureated scientists, such as Dr. Linus Pauling were yet struggling to comprehend the biochemical structure of polypeptide chains and proteins, it was already known, mainly by Porter's experiments, that the hydrolysis of antibodies by papain results not only in the inactivity of the antibody, but produced also an inhibitory factor that competes by their specific antigen with the correlated untreated antibodies [40-42]. This antibody-inhibitory fraction, obtained by hydrolysis of human immunoglobulins by means of papain, was studied independently by several investigators and referred by diverse names until 1964 when a committee of the WHO recommended the use of the nomenclature: Antigen-Binding Fragment (Fab) to refer to the inhibitory fragments produced by papain $[43,44]$. Papain cleaves the upper hinge of antibodies, producing three fragments: two $50 \mathrm{KDa}$ Fab fragments and one $50 \mathrm{KDa}$ crystallizable fragment (Fc), losing its capacity of agglutination, precipitation, opsonization and lysis [45-47].

To evaluate the possibility that the initial antigen-specific reconnaissance phenomena observed in the ex vivo challenge of the LAIT is mediated by antibodies, we designed a study comparing, side-by-side, the performance of LAIT with the paired same samples of plasma preincubated (or not) with papain before the antigen-specific ex vivo challenge test. The hypothesis was that a partial or total loss of the capacity to inhibit the leukocyte adherence produced by specific antigen, observed after the papain treatment, suggests that the initial reconnaissance phenomenon is mediated by specific antibodies. The mechanism could be just the cleavage of the specific free or cell-bounded antibodies and/or the production of autologous Fab fragments able to compete by the antigen's epitopes.

\section{Study Design and Methods}

After receiving institutional review board approval, 11 consecutives outpatients with clinical symptoms of allergy, diagnosed by allergy-skin tests as previously described, to diversified antigens, were invited, with informed consent formularies, according with the International Committee of Medical Journals Editors requirements of privacy and the principles of Helsinki, to voluntarily provide blood samples to perform $53 \mathrm{ex}$ vivo challenge tests with food, microbial and airborne allergens [48]. The first technical obstacle to design such experiment is that the LAIT must be performed with alive cells and so, we dispose of a limited amount of time to incubate the plasma with papain. Porter incubated papain and immunoglobulins during 16 hours at $37^{\circ} \mathrm{C}$, but by this time the plasma immune cells certainly are dead, turning impossible the LAIT [49]. However, Stockell and Smith studying the kinetics of papain action, stated, as quoted, that solutions of papain "which gave maximal enzyme activation were incubated for 30 minutes at $38{ }^{\circ} \mathrm{C}$ under various conditions of $\mathrm{pH}$ and in various organic solvents" [50]. So, as a proof of concept, we compared, side by side, the degradation of serum and plasma samples submitted to papain (or not) at $37{ }^{\circ} \mathrm{C}$ and $90{ }^{\circ} \mathrm{C}$ during 30 minutes by means of a Coomassie ${ }^{\circledR}$ Blue stained $15 \%$ resolving sodium-dodecyl sulfate acrylamide electrophoresis gel (SDS-PAGE) using a Mini Protean Tetra Cell apparatus (Bio-Rad, CA, USA) [51]. Aliquots of $5 \mu \mathrm{L}$ of the plasma and serum samples treated (or not) with papain at $37^{\circ} \mathrm{C}$ and $90{ }^{\circ} \mathrm{C}$ were applied to each lane. A 10-180 KDa molecular mass thermo scientific prestained protein ladder (PageRulerTM, Thermo Fisher, MA, USA) was used to identify approximate molecular weights. After electrophoresis the gel was stained with Thermo Fisher Coomassie ${ }^{\circledR}$ Blue to identify the protein distribution. All relevant and mandatory laboratory health and safety measures have been complied in the complete course of the experiments.

Certified and purified papain was purchased from Farma Vida Farmácia EPP (Americana - SP - Brazil). Ovalbumin was purchased from Sigma-Aldrich Brasil Ltda EPP (Cotia - SP Brazil). Food antigens for the cutaneous and ex vivo challenge tests were bought at a local marketplace, extracted and purified at our laboratory. Bacterial and house dust mite antigens were purchased from R.V. Manipulações Especiais Ltda (São Paulo - SP - Brazil). Transglutaminase was gently provided by Ajinomoto Co., Inc. (Limeira - SP - Brazil) to perform bovine beta-lactoglobulin (Bos D 5) polymerization, as previously described [29]. Plasma samples were collected in heparinized collection tubes. The duplicated plasma samples $(100 \mu \mathrm{L})$ were incubated (or not) during 30 minutes with papain $\left(10 \mu \mathrm{L}, 1 \mathrm{mg} / \mathrm{mL}, 37^{\circ} \mathrm{C}\right)$ before the ex vivo challenge with the specific antigen. The ex vivo challenge tests were performed as described previously, with minor alterations to fit the experiment with papain preincubation [29]. The plasma with high leukocyte content (buffy coat) was collected from the heparinized tube after one hour of sedimentation at $37{ }^{\circ} \mathrm{C}$ water bath (neither centrifugation, ficoll or dextran were employed) with a squeezable plastic Pasteur pipette and allocated into $1 \mathrm{~mL}$ polypropylene Eppendorf tubes kept under gentle agitation (200 rpm at $37^{\circ} \mathrm{C}$ ) with (or without, as used as control) antigen extract $(10 \mu \mathrm{L}$ of a solution with $1 \mathrm{mg} / \mathrm{mL})$. The plasma sample was kept under gentle agitation for 30 minutes at $37^{\circ} \mathrm{C}$. After incubation, the plasma was allocated into a standard Neubauer hemocytometer counting chamber with a plain, non-metallic glass surface and left to stand for 2 hours at $37^{\circ} \mathrm{C}$ in the humidified atmosphere of the covered water bath to allow leukocytes to adhere to the glass. Next, 
leukocytes were counted, and the coverslip was gently removed, followed by washing of the chamber by immersion in a beaker with PBS at $37^{\circ} \mathrm{C}$. A drop of PBS was subsequently added to the hemocytometer chamber, and a clean coverslip was placed over it. The remaining cells were counted in the same squares examined previously. The percentage of Leukocyte Adherence (LA) of each assay was estimated as: (the number of leukocytes observed on the hemocytometry chamber after washing / the number of leukocytes observed on the hemocytometry chamber before washing) x 100\%. The Leukocyte Adherence Ratio (LAR) was estimated based on the ratio between the LA from the antigen-specific challenged groups and the LA from the unchallenged control group: LAR = LA of challenged sample / LA of unchallenged control sample) x 100\%. To further calculated the Leukocyte Adherence Inhibition (LAI) it is enough to subtract the LAR from $100(\%)$.

\section{Statistical Analyses}

Statistical analyses were performed using GraphPad Prism software (version 5.0; GraphPad Software, Inc., San Diego, CA, USA). The data were reported as arithmetic means with 95\% confidence intervals (CI) and standard deviations (SD). Differences in the means of matched samples were assessed by paired t-tests. For all analyses, a p-value of less than 0.05 was considered significant. A whiskers-and-box plot graph was generated by the software.

\section{Results}

The Coomassie ${ }^{\circledR}$ Blue stained SDS-gel electroblotted with fresh plasma; plasma incubated at $37^{\circ} \mathrm{C}$; plasma incubated with papain at $37{ }^{\circ} \mathrm{C}$; plasma incubated with papain at $90^{\circ} \mathrm{C}$; fresh serum; serum incubated with papain at $37{ }^{\circ} \mathrm{C}$ and serum incubated with papain at $90{ }^{\circ} \mathrm{C}$, is displayed at Figure 1 . It shows a similar papaindisassembling of proteins of serum and plasma either at $37^{\circ} \mathrm{C}$ as well at $90{ }^{\circ} \mathrm{C}$. The Leukocyte Adherence Ratio (LAR \%) and Leukocyte adherence Inhibition (LAI \%) of 53 ex vivo allergen challenge tests monitored by the Leukocyte Adherence Inhibition Test of paired plasma pre-incubated (or not) with papain are displayed at Table 1. The mean of the LAR estimated among the 53 tests in the arm group not submitted to papain was $25.51 \%$ (LAI $=74.49 \%$ ). The mean of the LAR estimated among the 53 participants in the assays of the arm group submitted to papain was $52,17 \%$ (LAI $=47.83 \%$ ). The Box and whiskers plot graph comparing the LAR of the same paired plasma samples submitted (or not) to a preincubation with papain are displayed at Figure 2. The Prism GraphPad paired t test analysis between LAR (\%) of the same paired plasma samples submitted (or not) to a preincubation with papain are displayed at Appendix 1. The mean of the differences (26.66\%) between the two arms was considered significative by the paired t-test ( $\mathrm{p}$-value $<0.05$ ). Among the 53 analyzed ex vivo challenges, 30 (56.6\%) presented full adherence inhibition (LAI $=100 \%$ ) when processed without papain digestion. In this particular subgroup, 24 (80\%) presented leukocyte adherence similar to the unchallenged control plasma when the serum was submitted to papain, demonstrating that the papain completely abolished the mechanism of the inhibition of the adherence.

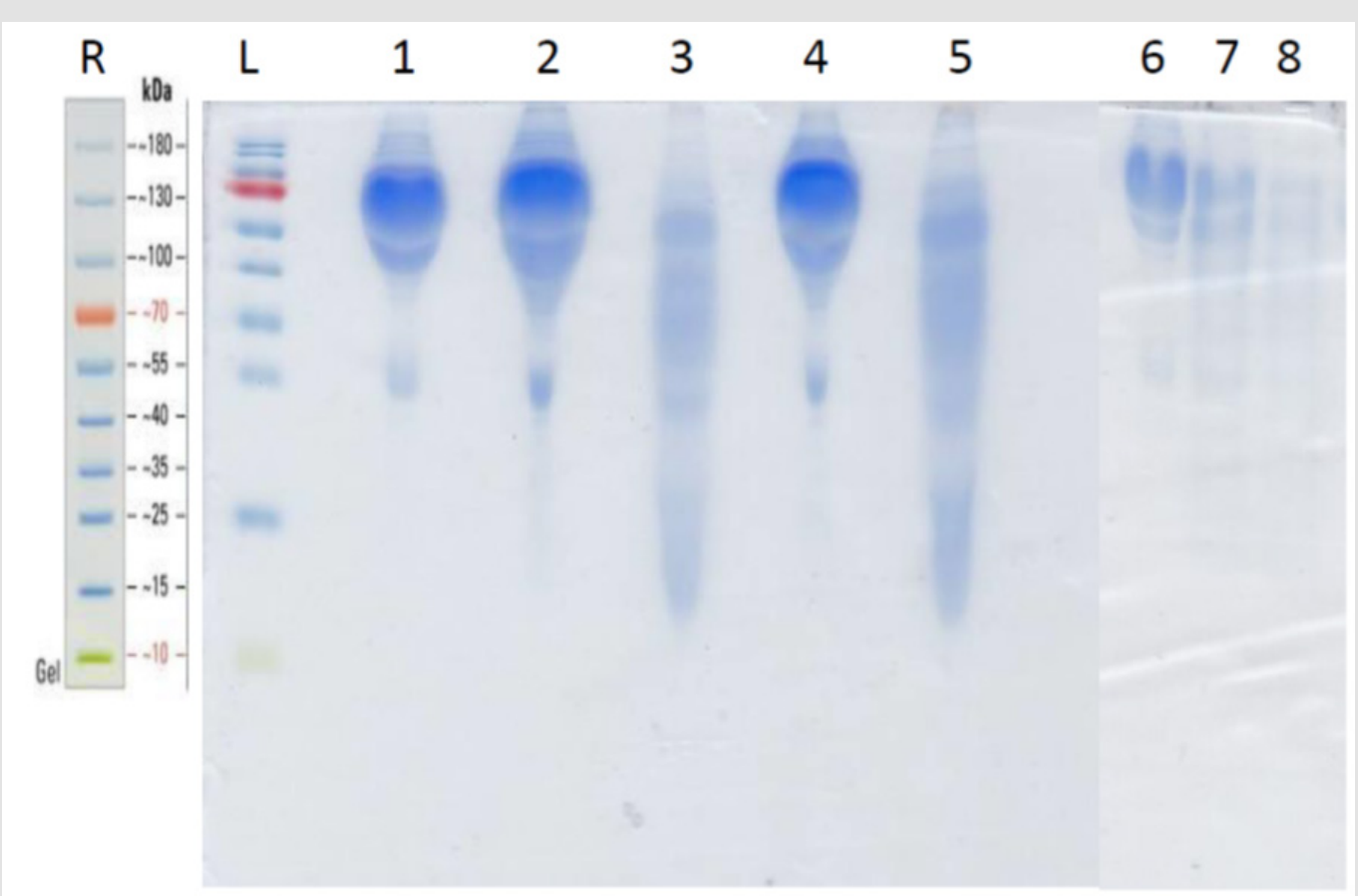

Figure 1: Coomassie ${ }^{\circledR}$ blue stained SDS-PAGE.

$\mathrm{R}=$ Thermo Fisher 10 - $180 \mathrm{KDa}$ molecular weight reference. $\mathrm{L}=$ prestained Page Ruler ${ }^{\mathrm{TM}}$ ladder lane; $1=$ fresh unmodified plasma; $2=$ plasma incubated at $37^{\circ} \mathrm{C}$ for 30 minutes; $3=$ plasma incubated with papain at $37{ }^{\circ} \mathrm{C}$ for 30 minutes; $4=$ plasma incubated at $90{ }^{\circ} \mathrm{C}$ for 30 minutes; $5=$ plasma incubated with papain at $90{ }^{\circ} \mathrm{C}$ for 30 minutes; $6=$ fresh serum; $7=$ serum incubated with papain at $37^{\circ} \mathrm{C}$ for 30 minutes; $8=$ serum incubated with papain at $90{ }^{\circ} \mathrm{C}$ for 30 minutes. 


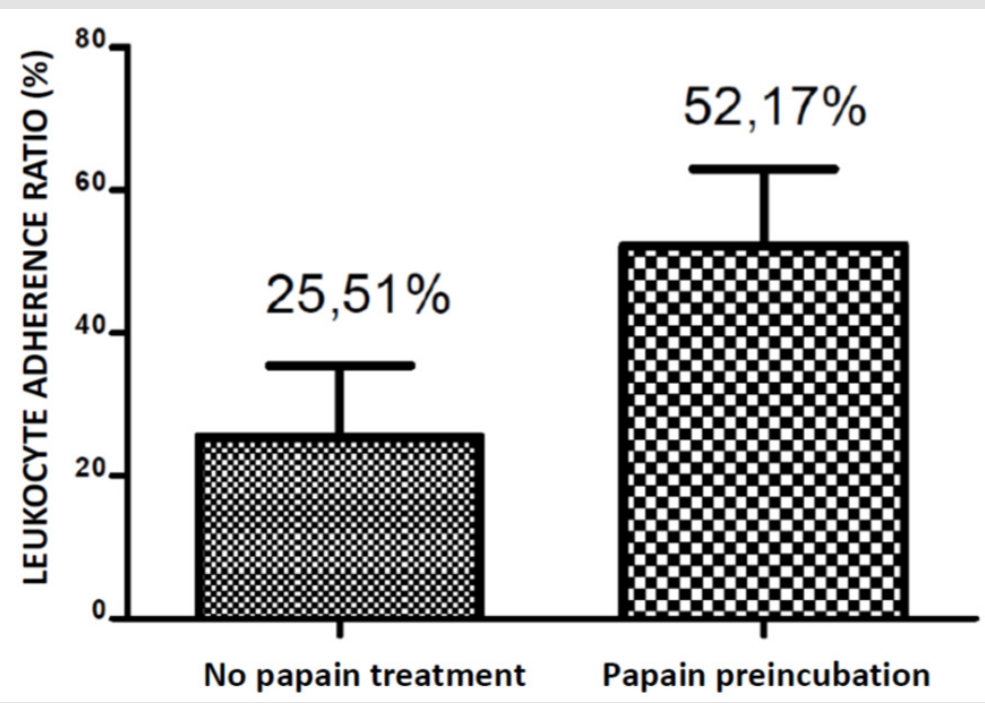

Figure 2: Box-and-whiskers plot graph comparing the adherence percentage of the same paired plasma samples submitted (or not) to a preincubation with papain.

Table 1: Leukocyte Adherence Ratio (\%) and Leukocyte adherence Inhibition (\%) of 53 ex vivo allergen challenge tests monitored by the Leukocyte Adherence Inhibition Test of paired plasma pre-incubated (or not) with papain.

\begin{tabular}{|c|c|c|c|c|c|}
\hline Patient & Antigen & LAR (\%) & LAI (\%) & LAR (\%) (papain) & LAI (\%) (papain) \\
\hline RL & Tuna meat (Tuna thunnini) & 0 & 100 & 81 & 19 \\
\hline RL & Bovine betalactoglobulin (Bos d 5) & 0 & 100 & 52 & 58 \\
\hline $\mathrm{RL}$ & Polymerized betalactoglobulin (Bos d 5) & 0 & 100 & 93 & 7 \\
\hline RL & Wheat (Triticum aestivum) & 0 & 100 & 88 & 12 \\
\hline RL & Malagueta pepper & 0 & 100 & 74 & 26 \\
\hline VHS & Bovine betalactoglobulin (Bos d 5) & 0 & 100 & 81 & 19 \\
\hline VHS & Polymerized betalactoglobulin (Bos d 5) & 0 & 100 & 54 & 46 \\
\hline VHS & Casein (Bos d 8) & 0 & 100 & 26 & 74 \\
\hline VHS & Soybean (Glycine max) & 0 & 100 & 34 & 66 \\
\hline $\mathrm{PA}$ & Bovine betalactoglobulin (Bos d 5) & 0 & 100 & 98 & 2 \\
\hline $\mathrm{PA}$ & Polymerized betalactoglobulin (Bos d 5) & 0 & 100 & 86 & 14 \\
\hline $\mathrm{PA}$ & Aspergillus fumigatus & 0 & 100 & 81 & 19 \\
\hline $\mathrm{PA}$ & Staphylococcus Toxoid & 0 & 100 & 95 & 5 \\
\hline $\mathrm{PA}$ & Staphylococcus aureus & 0 & 100 & 88 & 12 \\
\hline PA & Ovalbumin (Gallus domesticus) & 96 & 4 & 73 & 27 \\
\hline $\mathrm{PA}$ & Gluten (Triticum aestivum) & 81 & 19 & 72 & 28 \\
\hline YP & Dermatophagoides. Pteronyssinus & 68 & 32 & 98 & 2 \\
\hline YP & Bovine betalactoglobulin (Bos d 5) & 37 & 63 & 90 & 10 \\
\hline YP & Polymerized betalactoglobulin (Bos d 5) & 0 & 100 & 98 & 2 \\
\hline YP & Bovine meat (Bos domesticus) & 0 & 100 & 84 & 16 \\
\hline LC & Bovine betalactoglobulin (Bos d 5) & 72 & 18 & 100 & 0 \\
\hline LC & Polymerized betalactoglobulin (Bos d 5) & 33 & 67 & 100 & 0 \\
\hline LC & Redspottedshrimp (Penaeus brasiliensis) & 88 & 12 & 100 & 0 \\
\hline LC & Ovalbumin (Gallus domesticus) & 0 & 100 & 100 & 0 \\
\hline LC & Dermatophagoides. pteronyssinus & 0 & 100 & 100 & 0 \\
\hline MB & Bovine betalactoglobulin (Bos d 5) & 100 & 0 & 0 & 100 \\
\hline MB & Polymerized betalactoglobulin (Bos d 5) & 0 & 100 & 0 & 100 \\
\hline
\end{tabular}




\begin{tabular}{|c|c|c|c|c|c|}
\hline MB & Staphylococcus epidermidis & 76 & 24 & 6 & 94 \\
\hline MB & Staphylococcus Toxoid & 19 & 81 & 0 & 100 \\
\hline MB & Dermatophagoides. pteronyssinus & 0 & 100 & 88 & 22 \\
\hline MB & Latex (Hevea brasiliensis) & 84 & 16 & 98 & 2 \\
\hline KCC & Bovine betalactoglobulin (Bos d 5) & 94 & 6 & 0 & 100 \\
\hline KCC & Polymerized betalactoglobulin (Bos d 5) & 32 & 68 & 0 & 100 \\
\hline KCC & Dermatophagoides. pteronyssinus & 23 & 77 & 0 & 100 \\
\hline KCC & Latex (Hevea brasiliensis) & 0 & 100 & 0 & 100 \\
\hline FP & Dermatophagoides. pteronyssinus & 19 & 81 & 34 & 66 \\
\hline FP & Bovine betalactoglobulin (Bos d 5) & 0 & 100 & 26 & 74 \\
\hline FP & Polymerized betalactoglobulin (Bos d 5) & 26 & 74 & 63 & 47 \\
\hline $\mathrm{FP}$ & Casein (Bos d 8) & 0 & 100 & 60 & 40 \\
\hline FP & Soybean (Glycine max) & 84 & 16 & 67 & 43 \\
\hline APR & Bovine betalactoglobulin (Bos d 5) & 0 & 100 & 6 & 94 \\
\hline APR & Polymerized betalactoglobulin (Bos d 5) & 0 & 100 & 61 & 39 \\
\hline APR & Aspergillus fumigatus & 83 & 17 & 40 & 60 \\
\hline APR & Dermatophagoides. pteronyssinus & 90 & 10 & 51 & 49 \\
\hline MEF & Bovine betalactoglobulin (Bos d 5) & 10 & 90 & 0 & 100 \\
\hline MEF & Polymerized betalactoglobulin (Bos d 5) & 64 & 36 & 0 & 100 \\
\hline MEF & Dermatophagoides. pteronyssinus & 0 & 100 & 0 & 100 \\
\hline MEF & Chicken meat (Gallus domesticus) & 0 & 100 & 0 & 100 \\
\hline MEF & Pork meat (Sus domesticus) & 73 & 27 & 0 & 100 \\
\hline MEF & Latex (Hevea brasiliensis) & 0 & 100 & 0 & 100 \\
\hline MEF & Cacao bean (Theobroma cacao) & 0 & 100 & 0 & 100 \\
\hline $\mathrm{RDF}$ & Bovine betalactoglobulin (Bos d 5) & 0 & 100 & 57 & 43 \\
\hline RDF & Polymerized betalactoglobulin (Bos d 5) & 0 & 100 & 62 & 38 \\
\hline
\end{tabular}

\section{Discussion}

The complexity of the Gell and Coombs type II reactions is overwhelming. Despite the fully range of cytokines that are secreted in the plasma are not yet described, there are a myriad of membrane cells receptors that interact among them triggering intra-cellular and inter-cellular responses that result in the immune reaction. The LAIT is an ex vivo challenge test that relies on all this complexity but shows just the final result of the equation. The promptness of the response is highly suggestive that an adaptative antibody-mediated reaction orchestrates the cellular engagement. Here we describe a simple experiment, limited by the resources of our laboratory, with an antibody disassembler added to this complex system. Another limitation of the design of the study is that papain is also a foreign protein that may induce immune or allergic reactions and to work as an interferent of the ex vivo challenge test by itself, what may explain the cases where the leukocyte adherence decreased instead of increase [52]. So, the results mainly suggest, but do not necessarily prove, the participation of antibodies in this process. The experiment does not necessarily distinguish the cleavage of free antibodies from a possible cleavage of the membrane-bound antibodies, neither the proteolytic papain disassembling of another occasional unrecognized intermediate of the adherence-inhibition phenomena. A candidate for this disassembling is the IgG1+ memory B cells that are currently being studied as participant of food allergic reactions [53,54]. Memory B lymphocytes bearing antigenspecific antibodies on membrane receptors could theoretically provide rapid cytokine response to promote paracrine inhibition of glass adherence that could, by your turn, be blocked by papain disassembling and/or antigen-specific Fab competition [55]. We do not know the real extension of the antibody disassembling and we do not know the extension of the activity of the inhibitory Fab fragments furnished to the challenge chamber. Fab fragments produced by papain compete with the same antigen's epitopes to which membrane receptors and antibodies bound, what could, theoretically result in the abolishing of the inhibitory effect on the cellular adherence. We also do not exclude an eventual interference with another occasional innate reconnaissance system, but the high efficiency in blocking the inhibition of the adherence suggests that this mechanism is been activated by antigen-specific adaptive immune response.

Another inevitable visualization of the experiment is the concept of "effector and blocking antibodies" [56]. Operationally we can classify the antibodies according with their main function in two categories: the blocking antibodies and the effector antibodies. 
The effector antibody is an antibody with a functional and active Fc portion. It is by the Fc region that the antibody is able to bound to a cell receptor, activate it and occasionally initiates the complement cascade. These are mainly properties of antibodies of IgM, IgE and the IgG1, IgG2, IgG3 subclasses. Blocking antibodies are antibodies that bound to the antigens, but do not activate receptors cells or initiate the complement cascade, they predominantly block their epitopes, finishing the immune reaction. These are properties mainly of secretory IgA and IgG4 subclass $[57,58]$.In this experiment, the Fab fraction, theoretically acts as a blocking antibody since it possesses no Fc portion. The participation of allergen-specific IgG's subclasses and allergen-specific IgA antibodies in food allergy is not yet fully elucidated but their differential response on food allergic desensitization is currently under investigation [59].

Ours results also suggests that the ex vivo challenge LAIT is a functional model to demonstrate the presence of effector antibodies in the studied plasma. When the physicians quantify the presence of antibodies in the serum of the allergic patients to specific antigens (either IgE or unclassified $\operatorname{IgG}$ ) there is no indication that these circulating antibodies will clinically act as effector or blocking antibodies. Even the so requested free-serumIgE do not necessarily acts as an effector antibody when circulating by the serum. The effector IgE involved in allergic reactions, in reality, is not the free serum IgE, but the cell bounded IgE. At least theoretically, the free IgE may even act as a blocker antibody when trapping free allergens, competing with the real effectors: the cell-bounded IgE-receptors, the effective triggers of the Gell and Coombs' type I and type II hypersensitivity reactions. There are two kinds of membrane-bound receptors for IgE: the high affinity receptor FceRI, expressed on mast cells, neutrophils, basophils, monocytes and dendritic cells; and the low affinity receptor FceRII (CD23) expressed on B-cells, monocytes and dendritic cells [60]. Despite the free serum IgE correlates well with allergic disease, there are some allergic patients that present normal IgE serum levels at immunoassays. That is why it is actually proposed the measuring, by the employ of lactic acid on plasma, of the liberated cell bounded IgE as a tool to help physicians to diagnosis allergy [61]. This may happen when the allergy is produced by a non-IgEmediated mechanism, or even when the serum presence of nonIgE antibodies interferes with the IgE immunoassay, competing by the allergens' epitopes [62]. Finally, we must also consider the Gell and Coombs' type III hypersensitivity reaction that involves the bounding of free antibodies to circulating antigens that produces Complement-mediated reactions when larger immunocomplexes reach the tissues. This is one of the many "deserved-to-be-studied" mechanisms that could also possibly be "Complementing" the cellular phenomena observed on the LAIT positivity or, at least, on the regulation of the immune humoral activity by the Complement System [63]. We theorize that the ex vivo tests to detect Complement activation, theoretically, could be a valuable tool to achieve this objective if performed in association with the LAIT [64]. Because papain is known to cleave not only immunoglobulins but also other proteins, we cannot conclude from our results that a Gell and Coombs type II reaction is been demonstrated by the Leukocyte Adherence Inhibition Test. However, our results suggests that the leukocyte adherence inhibition phenomenon is mediated by an interaction of cells and specific antibodies and deserves further studies as an ex vivo challenge test tool for diagnosis of Gell \& Coombs type II hypersensitivity reactions.

\section{Declaration of All Sources of Funding}

Olivier CE, Pinto DG, Lima RPS and Santos RAPG received grant support from Instituto Alergoimuno de Americana.

\section{Disclosure of Potential Conflict of Interest}

The authors have declared that they have no conflict of interest.

\section{References}

1. Davies DH (2013) Immune System. In: John Wiley \& Sons L, editor. Immune System.

2. Akdis CA (2006) Allergy and hypersensitivity: mechanisms of allergic disease. Curr Opin Immunol 18: 718-726.

3. Ruíz-Argüelles A (1996) The cascade of the immune response. Current Therapeutic Research 57: 8-13.

4. Murphy K, Weaver C (2017) Janeway's immunobiology. $9^{\text {th }}$ (Edn,), Garland Science.

5. Oettgen H, Broide DH, Holgate ST, Church MK, Martinez FD (2012) Introduction to mechanisms of allergic disease. In: Elsevier, editor. Allergy (Fourth Edition). Edinburgh: W.B. Saunders, pp: 1-32.

6. Spertini O, Kansas GS, Munro JM, Griffin JD, Tedder TF (1991) Regulation of leukocyte migration by activation of the leukocyte adhesion molecule-1 (LAM-1) selectin. Nature 349: 691-694.

7. Spertini 0 (1996) [Regulation of leukocyte migration by adhesion molecules]. Schweiz Med Wochenschr 126: 1926-1934.

8. Boyden S (1962) The chemotactic effect of mixtures of antibody and antigen on polymorphonuclear leucocytes. J Exp Med 115: 453-466.

9. Halliday WJ (1979) Historical Background and Aspects of the Mechanism of Leukocyte Adherence Inhibition. Cancer Res 39: 558-563.

10. Li Y, Azuma A, Takahashi S, Usuki J, Matsuda K, et al. (2002) FourteenMembered Ring Macrolides Inhibit Vascular Cell Adhesion Molecule 1 Messenger RNA Induction and Leukocyte Migration: Role in Preventing Lung Injury and Fibrosis in Bleomycin-Challenged Mice. Chest 122: 2137-2145.

11. Bullen AW, Losowsky MS (1978) Comparison of a leucocyte adherence test with the leucocyte migration inhibition test and skin reactivity to PPD. Clin Exp Immunol 31: 408-413.

12. Fink A, Heller L, Eliraz A, Weisman Z, Miskin A, et al. (1987) Allergenspecific leukocyte adherence inhibition (LAI) assay: sensitivity, specificity and mechanism. Immunol Lett 16: 65-70.

13. Thomson DMP (1982) Assessment of immune status by the leukocyte adherence inhibition test. Academic Press, New York.

14.Dunn IS, Halliday WJ (1980) Subpopulations of splenic T and B lymphocytes producing and regulating leukocyte adherence inhibition factor. Cell Immunol56: 465-477. 
15. Vanto T, Smogorzewska EM, Viander M, Kalimo K, Koivikko A (1987) Leukocyte migration inhibition test in children with cow milk allergy. Allergy 42: 612-618.

16. Appelboom T, Famaey JP, Gortz R, Wybran J (1981) Effect of levamisole on leukocyte adherence inhibition. Agents Actions 11: 604-605.

17. Fink A, Bibi H, Eliraz A, Tabachnik E, Bentwich Z (1985) Leukotrienes (LTC4, LTD4) confer glass non-adherence on leukocytes of asthmatic individuals. Dependency on cyclooxygenase products and calcium ion. Immunol Lett 10: 319-323.

18. Fink A, Shahin R, Eliraz A, Bibi H, Berkenstadt H, et al. (1985) Interferon modulates the leukotriene $\mathrm{C} 4$-induced non-adherence properties of leukocytes: acquisition of an asthmatic phenotype. Immunol Lett 10: 159-163.

19. Iwabuchi K, Yamashita T (1990) Platelet-derived neutrophil adherenceinhibiting factor in humans. Blood 76: 2368-2373.

20. Nordqvist B, Rorsman H (1967) Leucocytic migration in vitro as an indicator of allergy in eczematous contact dermatitis. Trans St Johns Hosp Dermatol Soc 53: 154-159.

21. Lampert F, Dietmair E (1973) A leukocyte adherence inhibition test for cell-mediated immunity. Klin Wochenschr 51: 198-199.

22. Kuratsuji T (1981) Studies on leukocyte adherence inhibition test. Part I. Studies on mechanisms of leukocyte adherence inhibition. Keio J Med 30: 53-63.

23. Kuratsuji T (1981) Studies on leukocyte adherence inhibition test. Part II. Clinical applications of LAI test to detect delayed type hypersensitivity in infants and children. Keio J Med 30: 65-69.

24. Butler HL, Byrne WJ, Marmer DJ, Euler AR, Steele RW (1981) Depressed Neutrophil Chemotaxis in Infants with Cow's Milk and/or Soy Protein Intolerance. Pediatrics 67: 264

25. Ashkenazi A, Levin S, Idar D, Or A, Rosenberg I, et al. (1980) In Vitro Cell-Mediated Immunologic Assay for Cow's Milk Allergy. Pediatrics 66 399-402.

26. Olivier CE, Santos RAPG, Lima RPS, Argentão DGP, Silva GKM, et al. (2014) A Novel Utility for an Old Method: The Leukocyte Adherence Inhibition Test Is an Easy Way to Detect the Immunoreactive Interference of the Collection Tube Anticoagulant on Cellular Immunoassays. Journal of Cell Adhesion.

27. Fink A, Bibi H, Eliraz A, Schlesinger M, Bentwich Z Ketotifen (1986) Disodium cromoglycate, and verapamil inhibit leukotriene activity: determination by tube leukocyte adherence inhibition assay. Ann Allergy 57: 103-106.

28. Powell AE, Sloss AM, Smith RN (1978) Leukocyte-Adherence Inhibition: A Specific Assay of Cell-Mediated Immunity Dependent on LymphokineMediated Collaboration between $\mathrm{T}$ Lymphocytes. The Journal of Immunology 120: 1957-1966.

29. Olivier CE, Lima RPS, Pinto DG, Santos RAPG, Silva GKM, et al. (2012) In search of a tolerance-induction strategy for cow's milk allergies: significant reduction of beta-lactoglobulin allergenicity via transglutaminase/cysteine polymerization. Clinics 67: 1171-1179.

30. Gell PGH, Coombs RRA (1968) Classification of Allergic Reactions Responsible for Clinical Hypersensitivity and Disease. In: Gell PGH, Coombs RRA, editors. Clinical Aspects of Immunology. $2^{\text {nd }}$ (Edn.), Oxford: Blackwell Scientific Publications, pp: 575-596.

31. Mora J, Riggs EK, Fu J, MacGlashan DW, Fox SA, et al. (2009) Expression of the high affinity IgE receptor by neutrophils of individuals with allergic asthma is both minimal and insensitive to regulation by serum IgE. Clinical immunology (Orlando, Fla.) 132: 132-140.

32. Ikuta K, Takami M, Kim CW, Honjo T, Miyoshi T, et al. (1987) Human lymphocyte Fc receptor for IgE: sequence homology of its cloned cDNA with animal lectins. Proceedings of the National Academy of Sciences of the United States of America 84: 819-823.

33. Stone KD, Prussin C, Metcalfe DD (2010) IgE, mast cells, basophils, and eosinophils. The Journal of allergy and clinical immunology 125 : S73-S80.

34. Ochensberger B, Daepp G, Rihs S, Dahinden C (1996) Human blood basophils produce interleukin-13 in response to IgE- receptordependent and -independent activation. Blood 88: 3028-3037.

35. Maurer D, Fiebiger E, Reininger B, Wolff-Winiski B, Jouvin MH, et al. (1994) Expression of functional high affinity immunoglobulin E receptors (Fc epsilon RI) on monocytes of atopic individuals. J Exp Med 179: 745-750.

36. Uzzaman A, Cho SH (2012) Chapter 28: Classification of hypersensitivity reactions. Allergy and Asthma Proceedings 33: S96-S9.

37. Monti R, Basilio CA, Trevisan HC, Contiero J (2000) Purification of Papain from Fresh Latex of Carica papaya. Brazilian Archives of Biology and Technology 43: 501-517.

38. P0078 - Papain - Carica papaya.

39. Amri E, Mamboya F (2012) Papain, a Plant Enzyme of Biological Importance: A Review. American Journal of Biochemistry and Biotechnology 8: 99-104.

40. Pauling L, Corey RB (1951) The pleated sheet, a new layer configuration of polypeptide chains. Proc Natl Acad Sci U S A 37: 251-256.

41. Pauling L, Corey RB, Branson HR (1951) The structure of proteins; two hydrogen-bonded helical configurations of the polypeptide chain. Proc Natl Acad Sci U S A 37: 205-211.

42. Porter RR (1950) The formation of a specific inhibitor by hydrolysis of rabbit antiovalbumin. Biochem J 46: 479-484.

43. Franklin EC (1964) Structural Studies of Human 7s Gamma-Globulin (G Immunoglobulin). Further Observations of a Naturally Occurring Protein Related to the Crystallizable (Fast) Fragment. J Exp Med 120: 691-709.

44.(1964) Nomenclature-Committee. A nomenclature for human immunoglobulins. Bulletin of the World Health Organization 30: 447.

45. Porter RR (1959) The hydrolysis of rabbit gamma-globulin and antibodies with crystalline papain. Biochem J 73: 119-126.

46. Porter RR (1958) Separation and isolation of fractions of rabbit gammaglobulin containing the antibody and antigenic combining sites. Nature 182: 670-671.

47. Brezski RJ, Jordan RE (2010) Cleavage of IgGs by proteases associated with invasive diseases: an evasion tactic against host immunity? MAbs 2: $212-220$

48. Olivier CE, Argentão DGP, Santos RAPG, Silva MD, Lima RPS, et al. (2013) Skin scrape test: an inexpensive and painless skin test for recognition of immediate hypersensitivity in children and adults. The Open Allergy Journal 6: 9-17.

49. Porter RR (1959) The hydrolysis of rabbit y-globulin and antibodies with crystalline papain. Biochem J 73: 119-126.

50. Stockell A, Smith EL (1957) Kinetics of papain action. I. Hydrolysis of benzoly-L-argininamide. J Biol Chem 227: 1-26.

51. Weber K, Pringle JR, Osborn M (1972) Measurement of molecular weights by electrophoresis on SDS-acrylamide gel. Methods Enzymol 26 PtC: $3-27$.

52. Mansfield LE, Bowers CH (1983) Systemic reaction to papain in a nonoccupational setting. Journal of Allergy and Clinical Immunology 71 : 371-374. 
53. Jiménez-Saiz R, Ellenbogen Y, Koenig JFE, Gordon ME, Walker TD, et al. (2019) IgG1+ B-cell immunity predates IgE responses in epicutaneous sensitization to foods. Allergy 74: 165-175.

54. Bruton K, Spill P, Vohra S, Baribeau O, Manzoor S, et al. (2020) Interrupting reactivation of immunological memory diverts the allergic response and prevents anaphylaxis. Journal of Allergy and Clinical Immunology.

55. Satitsuksanoa P, Van de Veen W, Akdis M (2020) B cells in food allergy. J Allergy Clin Immunol.

56. Vizzardelli C, Gindl M, Roos S, Möbs C, Nagl B, et al. (2018) Blocking antibodies induced by allergen-specific immunotherapy ameliorate allergic airway disease in a human/mouse chimeric model. Allergy 73 851-861.

57. Favre L, Spertini F, Corthesy B (2005) Secretory IgA Possesses Intrinsic Modulatory Properties Stimulating Mucosal and Systemic Immune Responses. J Immunol 175: 2793-2800.

58. Aalberse RC, Schuurman J (2002) IgG4 breaking the rules. Immunology 105: 9-19.

ISSN: 2574-1241

DOI: 10.26717/BJSTR.2021.36.005869

Celso Eduardo Olivier. Biomed J Sci \& Tech Res

(C) (P) This work is licensed under Creative

Submission Link: https://biomedres.us/submit-manuscript.php
59. Sugimoto M, Kamemura N, Nagao M, Irahara M, Kagami S, et al. (2016) Differential response in allergen specific IgE, IgGs, and IgA levels for predicting outcome of oral immunotherapy. Pediatr Allergy Immunol 27: 276-282.

60. Dehlink E, Baker AH, Yen E, Nurko S, Fiebiger E (2010) Relationships between levels of serum IgE, cell-bound IgE, and IgE-receptors on peripheral blood cells in a pediatric population. PLoS ONE 5: e12204-e.

61. Qiu C, Zhong L, Huang C, Long J, Ye X, et al. (2010) Cell-bound IgE and plasma $\operatorname{IgE}$ as a combined clinical diagnostic indicator for allergic patients. Scientific Reports 10: 4700.

62. Aalberse RC, Aalberse JA (2016) Molecular Allergen-Specific IgE Assays as a Complement to Allergen Extract-Based Sensitization Assessment. J Allergy Clin Immunol Pract 3: 863-869.

63. Carroll MichaelÂ C, Isenman DavidÂ E (2012) Regulation of Humoral Immunity by Complement. Immunity 37: 199-207.

64. Yuan X, Yu J, Gerber G, Chaturvedi S, Cole M, et al. (2020) Ex vivo assays to detect complement activation in complementopathies. Clinical Immunology 221: 108616.

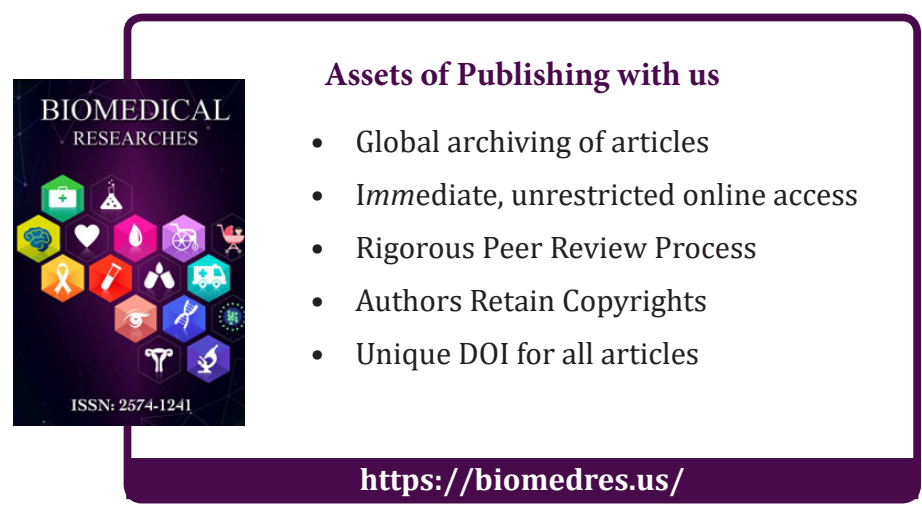

